\title{
SEISMIC SIGNALS ASSOCIATED WITH AVALANCHES
}

\author{
By William St. Lawrence and Thomas R. Williams* \\ (Department of Earth Sciences, Montana State University, Bozeman, Montana 597 I 5, U.S.A.)
}

\begin{abstract}
A seismic survey was conducted during the winter of 1974-75 to determine the extent to which signals from avalanches can be detected using standard seismic techniques. The results of this investigation show that signals associated with avalanching snow-packs have characteristic patterns which differentiate them from signals of extraneous origin. The records of several of these signals are presented and discussed.

RÉsumÉ. Signaux sismiques associés aux avalanches. On a conduit pendant l'hiver $1974-75$ une campagne d'observation sismique pour déterminer jusqu'à quel point on peut détecter des signaux émis par des avalanches avec les méthodes sismiques classiques. Les résultats de ces recherches montrent que les signaux associés aux avalanches ont des caractéristiques propres qui les distinguent de ceux d'origine externe. Les enregistrements de plusieurs de ces signaux sont présentés et discutés.

Zusammenfassung. Seismische Signale, verknüpft mit Lawinen. Zur Bestimmung des Ausmasses, in dem Signale von Lawinen mit normalen seismischen Verfahren entdeckt werden können, wurde im Winter 1974/75 ein seismisches Programm durchgeführt. Die Ergebnisse dieser Untersuchung zeigen, dass Signale, die von abgehenden Schneemassen herrühren, charakteristische Muster aufweisen, die sie von Signalen andren Ursprungs unterscheiden. Die Aufzeichnungen einiger dieser Signale werden vorgelegt und diskutiert.
\end{abstract}

\section{INTRODUCTION}

During the winter of $1974-75$ a broad-band acoustical study was undertaken to evaluate the applicability of acoustic emission techniques to detect instabilities associated with avalanche release. As part of this program, a seismometer was installed to monitor any ground and snow movement associated with the development of such instability.

Previous research (Ives and others, 1973) conducted on the seismicity associated with avalanche release indicated that the results obtained were generally inconclusive. The major problem encountered was the inability to differentiate the seismic signals of avalanches from seismic noise induced by other sources.

To minimize the problem of signal identification in the present study, the seismometer was located in the starting zone of an avalanche path as opposed to the run-out zone location. used in the previous investigation. The results obtained by changing the location of the geophone showed that seismic signals generated by snow movement have specific characteristics which make them easily distinguished from signals generated by extraneous sources. It was also found that although characteristic patterns can be recognized and associated with major snow events, several signal types which are not easily identifiable are also present. Comparison with records made without snow cover indicate that some of the unidentified signals may also be traceable to sources within the snow pack.

\section{Field LOCATION}

The study site for this program was located in the Bridger Range of south-western Montana,

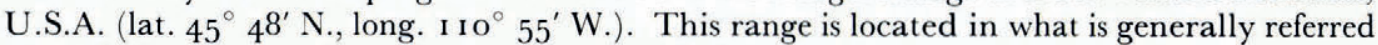
to as the intermountain region and has a mid-alpine environment. The Bridger Range is a north-south trending range with many active avalanche paths on both east and west flanks.

The path chosen for study is east-facing and is typical in terms of slope, aspect, angle, elevation, loading pattern, and size of many of the slide paths on the eastern side of the range. The starting zone of this path is a well-defined nivation hollow of simple geometry with a

* Now at Department of Geophysics, University of Utah, Salt Lake City, Utah 84100 , U.S.A. 
slope angle of $40^{\circ}$. The bed surface of this path is weathered limestone with a few coherent limestone outcrops. When this slide runs to the full extent of its path it drops a vertical distance of approximately $500 \mathrm{~m}$ and covers a horizontal distance of $1.2 \mathrm{~km}$.

The path selected for instrumentation normally is not subjected to any artificial stabilization methods. It is bounded on the north by a winter recreation area that has an intensive avalanche control program and to the south by many uncontrolled slide paths. Situated in this manner observation of both controlled and uncontrolled slopes can be made.

\section{INSTRUMENTATION SYSTEM}

The transducer used in this investigation was a $28 \mathrm{~Hz}$ vertically mounted reflection geophone with $28 \%$ damping. The geophone was selected for several reasons. Based on the results presented by Ives and others (1973) it was felt that by using a relatively high-frequency sensing device a great deal of extraneous noise would be eliminated and only seismic activity in the vicinity of the local path would be detected. In retrospect this was an erroneous decision since the characteristic signals from avalanches can generally be distinguished from other events. A lower-frequency transducer would have extended the range surveillance and given increased sensitivity at the low frequencies.

The second important factor in utilizing this geophone was that, as originally conceived, seismic occurrences were to be recorded on an event-counting basis. The transducer was therefore used in an underdamped mode to increase peak sensitivity. It was subsequently

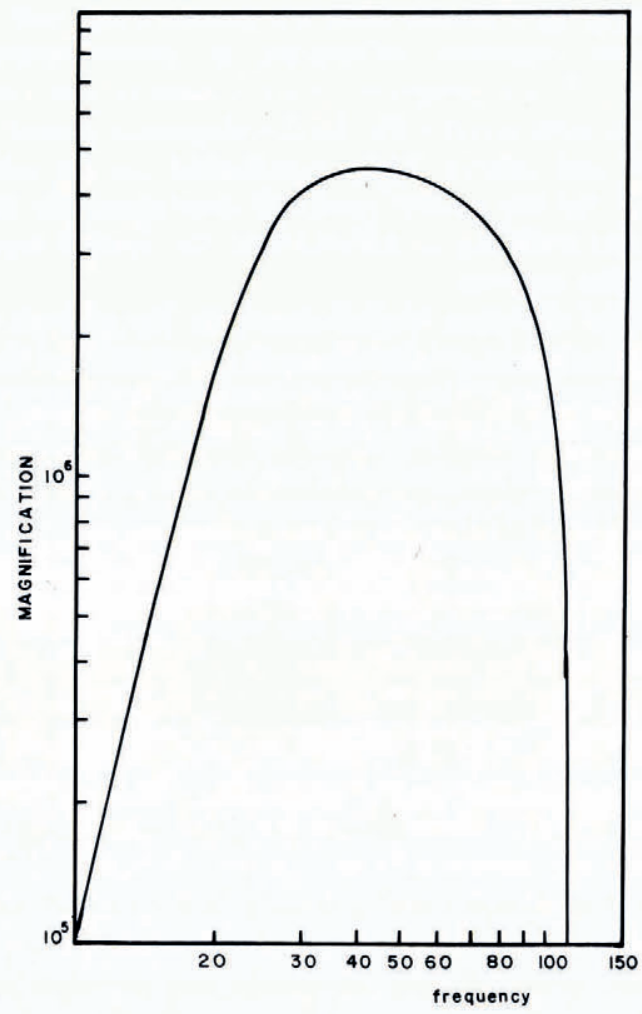

Fig. I. System response characteristics, logarithm of magnification versus logarithm of frequency. 
determined that event-monitoring was not feasible for low-frequency signals and an analogue recording of seismic signals was required. With the analogue recording system, the low damping of the transducer introduced an unwanted resonance in the system. To obtain optimum coupling the transducer was cemented into a rock outcrop.

The analogue signal was recorded on a smoked paper drum using a Sprengnether Model MEQ-8oo Microearthquake Recorder. Figure $\mathrm{I}$ is a $\log -\log$ plot of the transducer-amplifierrecorder magnification versus frequency. It can be observed from this figure that the maximum response of the system is in the region of $50 \mathrm{~Hz}$ with the sensitivity dropping above and below this value. Due to the relatively high-frequency response of the system and the type of recorder used, little information can be obtained in regard to the frequency content of the signals recorded. Information is however obtained from the envelope of the signals.

\section{Characteristic signals}

In monitoring seismic signals from snow, difficulty arises in clearly defining those signals which emanate from within the snow pack and those which are of extraneous origin. For the purpose of this paper we will discuss only those signals for which we are reasonably certain of the snow origin. Among these are signals from slab avalanches, loose-snow avalanches, cornice fall and internal fracture of the snow.

Figure $2 \mathrm{a}$ shows the seismic trace obtained from a naturally released hard-slab avalanche directly over the seismometer. The snow depth at the time of release was approximately three meters. This particular avalanche had a crown fracture one meter in height. The seismometer was located $50 \mathrm{~m}$ down-slope from the crown fracture.

Due to the high-frequency nature of this signal, its frequency distribution cannot be determined. An important characteristic which distinguishes it as a slab avalanche can however be identified. This is the initial spike associated with slab fracture, this is followed by a quiescent period of approximately $0.5 \mathrm{~s}$, and a gradual increase of the signal intensity as the slab accelerated down the slope. It is this latter signal characteristic that makes the signal easily identifiable as an avalanche as opposed to a local earthquake.

Figure $2 \mathrm{~b}$ shows the trace produced by a loose-snow avalanche. This record is similar to that shown in Figure 2a except that it lacks the initial spike associated with the fracture of the snow slab.

The third type of signal related to major snow movement is that of the fracturing of cornices. This may or may not lead to avalanche release. Figure 3 shows the trace obtained from a cornice release which did not produce an avalanche. This signal can generally be identified by the initial fracture of the cornice (1), the impact of the cornice on the slope (2), and the rolling of the cornice block down the slope.

The last type of seismic signal associated with snow movement is unlike the others in that it produces no observable displacement of the snow pack. This signal is inferred to be of snow origin since it is not detected on seismic records in the absence of snow cover. It is hypothesized that these signals represent the onset of small fractures within the snow pack. It is significant to note that generally these signals occur during periods of specific slope instability, however at this time insufficient data exist to identify them positively as precursors to major slope fracture. Figure 4 shows a cluster of six of these signals (identified by arrows) over a time period of approximately $120 \mathrm{~min}$. In this figure the time between adjacent points on any two lines is $10 \mathrm{~min}$ and the time between the offsets on any given line is one minute.

Examination of these signals indicates that the source is located in relatively close proximity to the transducer and is impulsive in nature. This signal may be induced by fracture in a localized region of high internal stress within the snow pack. Under favorable conditions, this local fracture may develop sufficient energy to propagate throughout the pack, causing catastrophic failure of the snow slope. 


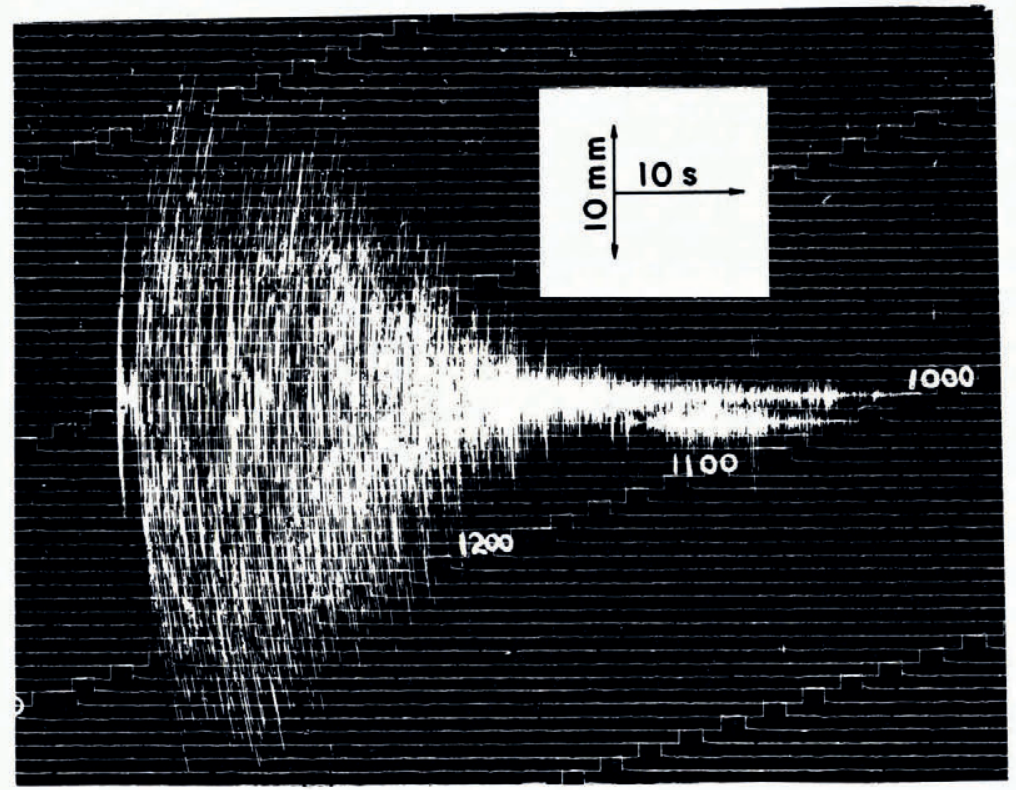

(a)

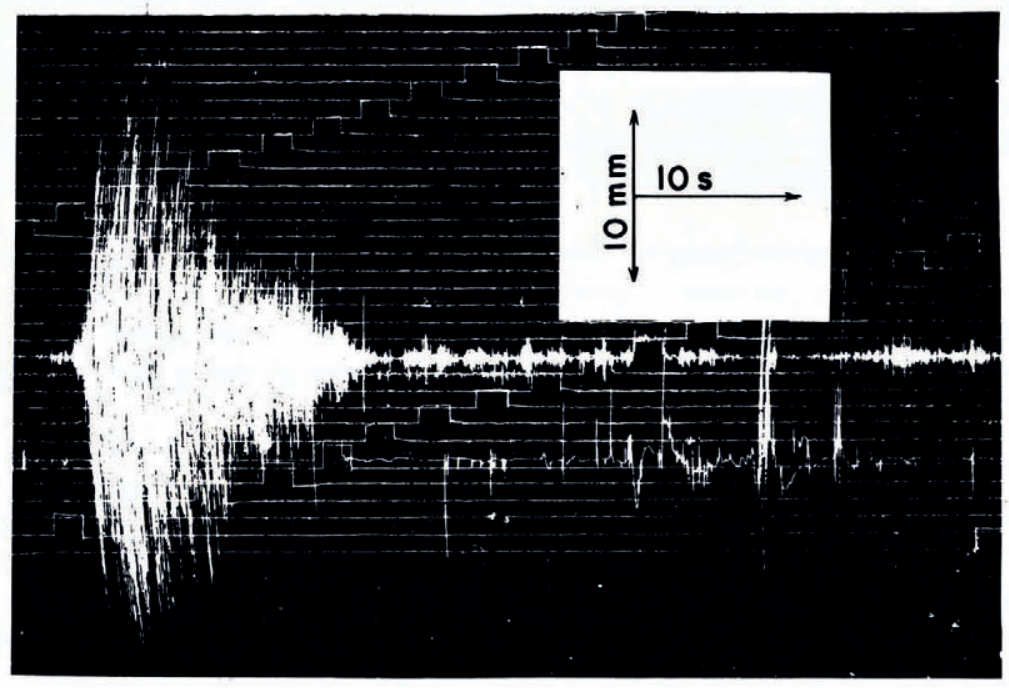

(b)

Fig. 2. (a) Recorder trace of a naturally released hard-slab avalanche; (b) trace recorded by the release of a loose-snow avalanche. 


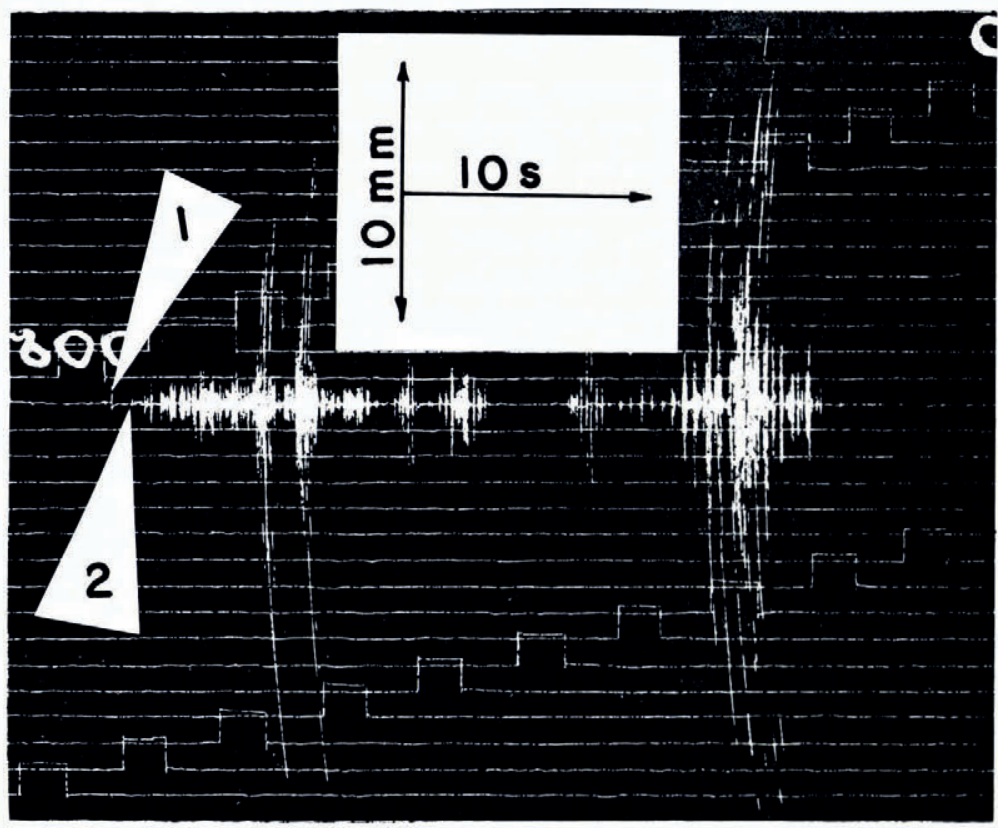

Fig. 3. Signal record from the fracture and fall of a snowe cornice. (1) fracture of cornice. (2) impact of cornice on slope.

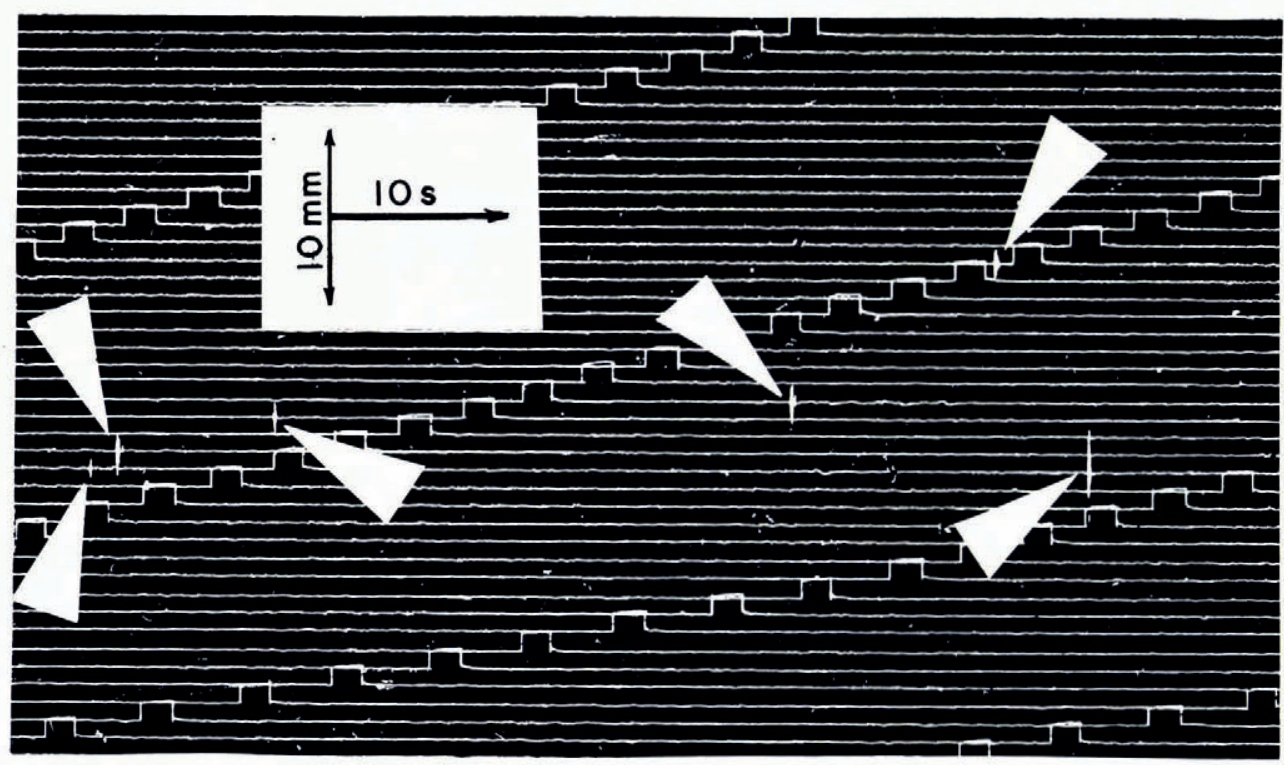

Fig. +. Low-amplitude impulsive signals possibly associated with internal slab fracture. These signals are marked by arrows in this figure. 


\section{Discussion}

The results of the investigation indicate that seismic monitoring of avalanche paths is a highly successful technique for detecting area-wide avalanche activity. The results discussed have dealt with seismic signals emanating from a single slide path. It should be noted that signals from avalanche activity at distances of one to two kilometers can also be detected. For distant signals much of the clarity associated with close-in signals is lost, but sufficient characteristics exist to make positive identification of the snow-related signal sources.

It was determined during this investigation that a high correlation exists between instabilities detected by seismic monitoring of our study slope and the onset of widespread instability throughout the range. This result indicates that seismic monitoring of a major slide path may be a valuable aid to avalanche forecasting, especially as it relates to forecasting delayed-action avalanches where strong reliance on meteorologic variables may not be sufficient to develop an accurate forecast. This method also provides a reliable technique for making observations in the starting zones of major slide paths where it may not be practical to make site visitations.

\section{ACKNOWLedgements}

The authors would like to extend a special thanks to Dr Anthony Qamar of the University of Montana for making available the microearthquake recorder used in this study. We would also like to thank the Bridger Bowl ski area staff for their cooperation throughout our field season.

This work was made possible through grants from the U.S. Army Research Office (DA-ARO-D-3I-I 24-7I-G59) and from the National Science Foundation (NSF GA-3943). The support from these agencies is gratefully acknowledged.

$M S$. received 3 November 1975 and in revised form 16 February 1976

\section{REFERENCE}

Ives, J. D., and others. 1973. Development of methodology for evaluation and prediction of avalanche hazard in the San Juan mountain area of southwestern Colorado. Interim report for period August 1972-August 1973, [by] 7. D. Ives, J. C. Harrison, R. L. Armstrong. Boulder, Colorado, Institute of Arctic and Alpine Research. (INSTAAR-I 4-o67 I $55^{-2}$.) 